\title{
Finite Element Analysis of Reinforced Concrete Pile Cap using ATENA
}

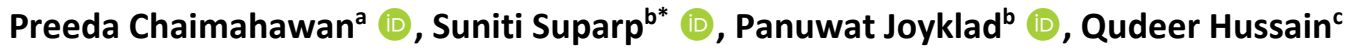

a School of Engineering, University of Phayo, Phayao, Thailand. E-mail: preeda.ch@up.ac.th

${ }^{b}$ Department of Civil and Environmental Engineering, Srinakharinwirot University, Thailand. E-mail: suniti@g.swu.ac.th, panuwatj@g.swu.ac.th

${ }^{c}$ Center of Excellence in Earthquake Engineering and Vibration, Department of Civil Engineering, Chulalongkorn University, Thailand. E-mail: ebbadat@hotmail.com

\section{*Corresponding author}

https://doi.org/10.1590/1679-78256290

\begin{abstract}
Reinforced concrete (RC) Pile cap, a thick reinforced concrete block, is constructed to provide a connection between a structure and multiple single piles. In the existing design methods, the behavior of RC pile cap is usually considered as a rigid body and resulting forces or reactions on piles are assumed equal. However, in actual conditions, there is a possibility of bending of pile cap and un-equal reactions or forces on piles. This study represents a detailed finite element analysis of RC eight-pile cap by using a computer program ATENA. ATENA serve as rational tools to explain the behavior of RC structures. Research parameters included different types of loading conditions, analysis types such as linear and non-linear, support conditions, length of pile, strength of concrete and thickness of pile cap. The finite element analysis results indicate that the behavior of RC pile cap is not a rigid body and resulting forces or reactions are unequal. Also, it was observed that, support conditions, analysis type and thickness of RC pile cap had a significant effect on the global behavior of RC pile caps.
\end{abstract}

\section{Keywords}

Reinforced concrete, Pile cap, Finite element analysis, ATENA, strength of concrete, Rigid Body

\section{Graphical Abstract}
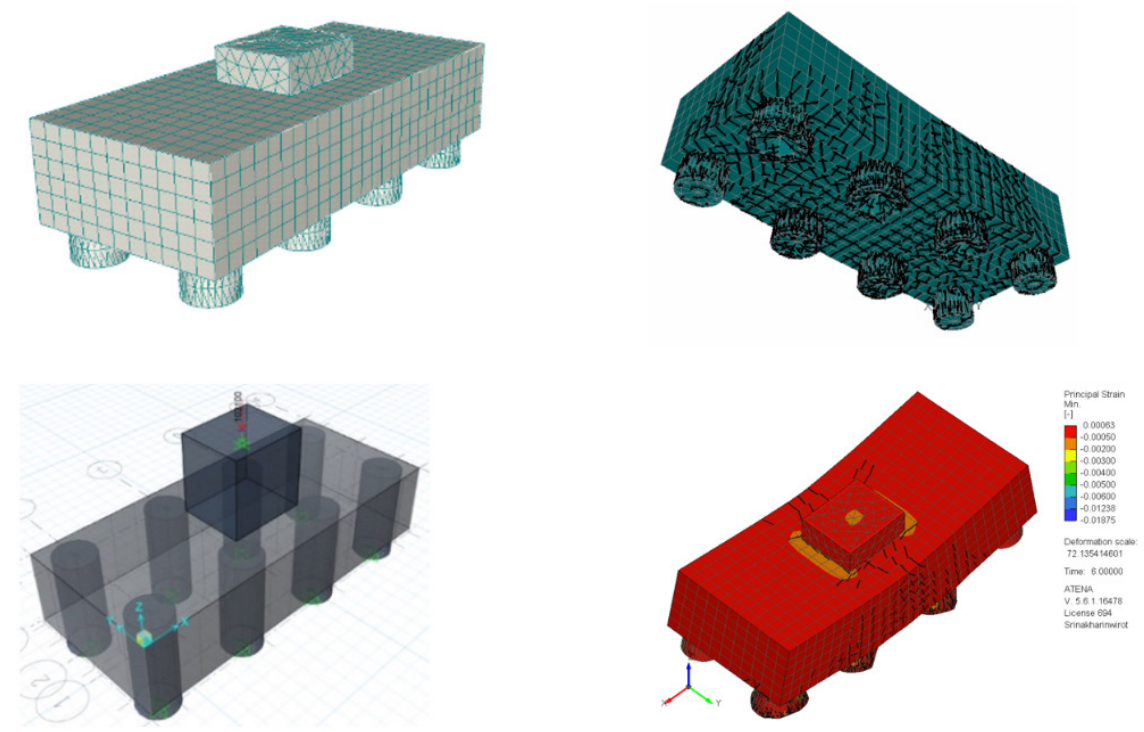

Received: October 13, 2020. In Revised Form: December 04, 2020. Accepted: December 20, 2020. Available online: January 15, 2021. https://doi.org/10.1590/1679-78256290

(i) Latin American Journal of Solids and Structures. ISSN 1679-7825. Copyright () 2021. This is an Open Access article distributed under the terms of the Creative Commons Attribution License, which permits unrestricted use, distribution, and reproduction in any medium, provided the original work is properly cited. 


\section{INTRODUCTION}

Reinforced concrete pile cap is defined as a thick block of RC concrete which is constructed to develop a connection between the column or pier and single or multiple piles. RC pile cap is a very important component of foundation and RC pile cap is usually design to transmit load from column to the piles. RC pile caps are usually designed for vertical loads, lateral or cyclic loads and overturning moments. Although RC pile cap is common component and widely used in the foundation, there is no specified procedure for the design of RC pile caps in the existing design codes. In the past different empirical rules have been established and which are now frequently used for the design of RC pile caps. In some codes, the distribution of strain is considered as linear along the depth of a member. Therefore, the behavior of RC pile cap is generally assumed as rigid body beam. In the design, usually longitudinal reinforcement is provided based on beam theory and adequate depth is provided to avoid punching shear.

To date extensive experimental research has been conducted on RC pile caps to investigate the suitability of the different design methods (Magade and Ingle 2020). In addition, laboratory tests have been carried out to understand the flexure and shear behavior of RC pile caps (Park et al. 2008). In 1973, Clarke JL investigated the suitability of strut-andtie method for the design of RC pile caps by performing series of tests on RC pile caps with foul piles. It was found that the strut-and-tie method is suitable for the design of RC pile caps. Further, it was observed that the in case of reinforcement provided in the form of grid pattern, the observed bearing capacity was observed lowest than other patterns of steel bars (Clarke 1973). In another study, Suzuki et al. also reported the suitability of the strut-and-tie method for the design of RC pile caps. The strut-and-tie method was also found more effective than other conventional methods, because in this method, tension forces are usually concentrated over the piles (Suzuki et al. 1998). An extensive experimental program was developed by Blévot and Frémy 1967. The test results indicate that RC pile caps having square pattern for steel bars resulted in higher load carrying capacity than the RC pile caps with grid pattern reinforcement. Further, author concluded that in RC pile caps, both shear and bending behaviors are associated with each other and ultimate failure of RC pile caps is mainly due to the punching shear (Blévot and Frémy 1967). Further, other researchers (Suzuki et al. 1999 and Suzuki et al. 2000) also supported these conclusions. Adebar et al. 1990 performed an experimental study on deep RC pile caps to find out the suitability of $\mathrm{ACl}$ building code procedures for the shear design of pile caps and strut-and-tie models. Authors concluded that $\mathrm{ACl}$ building procedure is not capable to accurately predict the experimental results because $\mathrm{ACl}$ building procedure neglects the amount of longitudinal reinforcement. Whereas, the predictions by strut-tie-models were found more accurate. In their study, the strain in the longitudinal steel bars were also monitored across the full width in each RC pile cap to investigate the accuracy of assumption of sectional method that that applied moments are unfirmly resisted by full width of RC pile caps or in other words, a uniform compression at the top of the RC pile caps. However, in the experiments, a non-uniform strain distribution was observed for steel bars at the top. Highest strains were observed at the middle whereas lowest strains were observed at the edges. This indicates that applied moments are mainly resisted by the middle portion of the RC pile caps as suggested by strutand-tie models approach (Adebar et al. 1990). The effect of longitudinal reinforcement on the shear strength of RC pile caps was further experimentally investigated by Sabnis and Gogate (1984). Authors found that reinforcement ratio over $0.2 \%$ had insignificant effect on the shear strength of the RC pile caps (Sabnis and Gogate 1984). The effect of longitudinal reinforcement on the shear strength of RC pile caps was also studied by Blévot and Frémy 1967; Clarke 1973; Suzuki and Otsuki 2002 ; Suzuki et al. 1998 and Suzuki K et al., 2000. However, these studies did not support the research findings of Sabnis and Gogate 1984. In 2000, Suzuki et al. investigated the influence of edge distance on the failure modes of RC pile caps. The results indicate that for a particular amount and type of longitudinal reinforcement there is decrease in the first cracking load and flexural capacity with a decrease in the edge distance (Suzuki K et al., 2000). Later in 2002, Suzuki and Otsuki further tested eighteen RC pile caps to investigate the shear failure of RC pile caps. The authors reported that most of the RC pile caps were mainly failed due to the shear and flexural failure was not observed (Suzuki and Otsuki 2002). The feasibility and theoretical predictions of strut-and-tie models were further investigated by Ahmed et al. (2009). The experimental results were compared with the theoretical predictions of strut-and-tie models. The authors concluded that the theoretical predictions by strut-and-tie models are in good agreement with the experimental results (Ahmed et al. 2009).

In addition to the experimental investigation on RC pile caps, extensive research efforts have been published in which structural behavior of RC pile caps is investigated through analytical and finite element analysis (Yang et al. 2020). In 1995, Sam and lyer, investigated the behavior of RC pile caps by using 3D (three dimensional) finite element analysis program. Different patterns of longitudinal steel bars were considered to investigate their effect on the structural behavior of RC pile caps. The analysis results in terms of load versus deflection, strain in the longtitudinal steel bars, and cracks were compared with the experimental results. It was found the finite element analysis results are in close agreement with the experimental results of RC pile caps (Sam and lyer 1995). Souza et al. 2007 conducted a non-linear 
finite element analysis of RC pile caps under generic loading. A non-linear finite element analysis (NLFEA) program was selected for use that was specifically written for predicting the behavior of a three-dimensional continuum of structural concrete subjected to a complex state of stress. For modeling the concrete behavior, a fracture-plastic model based on the classical orthotropic smeared crack formulation (CC3NonLinCementitious2) implemented by Cervenka et al. 2005 was applied. The results show that the predicted capacities are greater than those calculated from the adaptable strutand-tie model. The differences in the predicted behavior can be explained by the significant influence of the concrete tensile strength in the bottom region of the pile caps, which is not considered in the present formulation and in most codes of practice (Souza et al. 2007 and Cervenka et al. 2005). The finite element analysis of rigid RC pile cap was performed by Shen et al. by using variation analysis approach. In the finite element analysis shear stresses, tensile stresses, and deformations were investigated. The interaction between the soil and pile caps were modelled using Mindlin's solution. Further, in the finite element analysis, principle of minimum potential energy was adopted to capture the structural response of RC pile caps and piles. The finite element analysis results were compared with the experimental results and it was found that finite element analysis results are in well agreement with the test results (Shen et al. 2000).

Although, extensive experimental and analytical investigations have been carried out to investigate the behavior of $\mathrm{RC}$ pile caps and to check the suitability of the design methods. Almost in all previous studies, four-pile RC cap is considered both for experimental and analytical investigations. In addition, the behavior of the RC pile cap is mainly assumed as rigid body in those studies. As per author's knowledge there is no analytical study on the RC pile caps with number of piles greater than four and in case of six-pile cap or eight-pile cap, the validity of right body assumption is not yet clear. Therefore, the main objective of this study is to numerically investigate the structural behavior of eight-pile RC cap by using finite element method or FEM. A user friendly computer program "ATENA" was used for finite element analysis (FEA). The analysis parameters included were analysis type (such as linear and non-linear), type of element (such as solid and plate element), thickness or depth of pile cap and length of the piles. The analysis results were also compared with the conventional design methods. The finite element analysis results indicate that structural behavior of RC pile caps is flexible and bending was evidences. In addition, it was observed that thickness of RC pile caps and length of pile had a significant effect on the load carrying capacity of RC pile caps.

\section{Details of RC Pile Cap}

Recently, Mass Rapid Transit Authority (MRTA) Thailand has decided to adopt elevated monorail in Bangkok as a rapid transit system. The elevated structure is comprised of pre-cast girders and columns. Pre-cast columns are designed to erect at the site on a cast-in-place eight-pile reinforced concrete pile caps. The eight-pile RC cap was designed using conventional method. The RC pile cap of this study represents the typical details of eight-pile RC cap of elevated monorail transit system in Bangkok. The typical details of RC pile cap are shown in Figure 1. The length and width of RC pile cap were $13.2 \mathrm{~m}$ and $5.75 \mathrm{~m}$, respectively. Whereas, the height or thickness of RC pile cap was $2.80 \mathrm{~m}$. RC pile cap was constructed over eight piles (diameter $1.5 \mathrm{~m}$ ). A square column of size $3.0 \times 3.0$ meter was constructed at the center of the RC pile cap. A total number of 29 deformed bars (DB) of diameter $25 \mathrm{~mm}$ and 67 deformed bars of diameter 25 were provided at the top of RC pile cap in longitudinal and transverse direction, respectively. Whereas, at the bottom of RC pile cap, a total number of 57 deformed bars (DB) of diameter $25 \mathrm{~mm}$ and 67 deformed bars of diameter 25 were provided in longitudinal and transverse direction, respectively. The average yielding and tensile strength of deformed bar of diameter $25 \mathrm{~mm}$ was 560.6 MPa and $680 \mathrm{MPa}$, respectively. The average compressive strength of concrete was $42 \mathrm{MPa}$ (cylindrical strength $\mathrm{f}^{\prime} \mathrm{c}$ ).

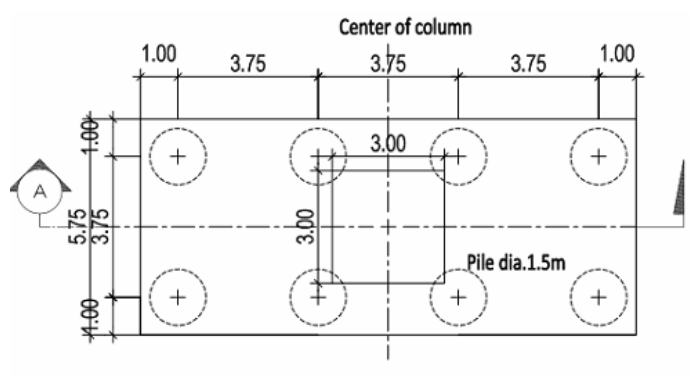

PLAN

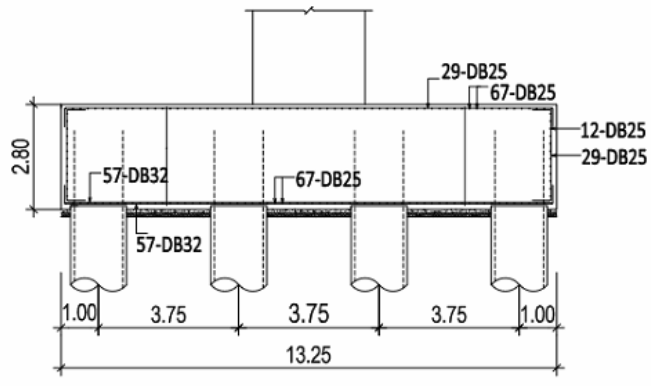

SECTION A

Figure 1 Dimensional and reinforcement detail of RC pile cap (units meter) 


\section{FINITE ELEMENTS MODELLING of RC PILE CAP}

In this study, a detailed finite element analysis program was planned to investigate the structural behavior of reinforced concrete (RC) eight-pile cap using computer program ATENA. ATENA is a tool for nonlinear engineering analysis of concrete structures (Červenka et al. 2000, Cervenka et al. 2002, Mello and Souza 2016). A total number of 16 finite element models were developed and simulated to study the effect of loading conditions (service and ultimate), support conditions (such as pin support and actual piles), element type (such as plate and solid), analysis type (linear and non-linear), length of pile, thickness of pile cap and strength of pile cap concrete on the structural behavior of RC eightpile cap. A detailed description of the finite element analysis program is summarized in Table 1 . Finite element models of RC pile cap P1 is shown in Figure 2a, and reinforcement details are shown in Figure 2b. Typical finite element models of RC pile caps with eight piles of different lengths are shown in Figure 3. The application of applied load at the center of columns is shown in Figure 4. The computer program ATENA contains different built-in material models for concrete, steel and other materials. A short discussion on different material models is given in the following sections and further details can be found in ATENA documentation (Cervenka et al. 2002). In this study, the end tip of the piles were modelled as pin supports and the soil and its role in supporting the structure were ignored. Also, the surrounding confinement of piles was ignored and the behavior of RC pile cap was only considered due to the service and design loads.

Table 1 Details of finite element models

\begin{tabular}{|c|c|c|c|c|c|c|c|c|}
\hline FE Model & Support & $\begin{array}{l}\text { Element } \\
\text { type }\end{array}$ & $\begin{array}{l}\text { Analysis } \\
\text { type }\end{array}$ & $\begin{array}{l}\text { Length of } \\
\text { pile (m) }\end{array}$ & $\begin{array}{l}\text { Strenght of } \\
\text { concrete } \\
\text { (MPa) }\end{array}$ & $\begin{array}{l}\text { Thickness } \\
\text { of pile cap }\end{array}$ & Type of load & $\begin{array}{l}\text { Column } \\
\text { size }(m)\end{array}$ \\
\hline P1 & Pin support & Plate & Linear & - & 42 & 2.8 & Ultimate & $3 \times 3$ \\
\hline P2 & Actual piles & Plate & Linear & 1.0 & 42 & 2.8 & Ultimate & $3 \times 3$ \\
\hline P3 & Pin support & Solid & Linear & - & 42 & 2.8 & Ultimate & $3 \times 3$ \\
\hline P5 & Pin support & Solid & Non-linear & - & 42 & 2.8 & Ultimate & $3 \times 3$ \\
\hline P6 & Actual piles & Solid & Non-linear & 1.0 & 42 & 2.8 & Ultimate & $3 \times 3$ \\
\hline P7 & Actual piles & Solid & Non-linear & 5.0 & 42 & 2.8 & Ultimate & $3 \times 3$ \\
\hline P8 & Actual piles & Solid & Non-linear & 10.0 & 42 & 2.8 & Ultimate & $3 \times 3$ \\
\hline P9 & Actual piles & Solid & Linear & 1.0 & 60 & 2.8 & Ultimate & $3 \times 3$ \\
\hline P11 & Actual piles & Solid & Linear & 1.0 & 42 & 4.0 & Ultimate & $3 \times 3$ \\
\hline P12 & Actual piles & Solid & Linear & 1.0 & 42 & 5.2 & Ultimate & $3 \times 3$ \\
\hline P13 & Actual piles & Solid & Non-linear & 1.0 & 42 & 2.8 & Service/Design & $3 \times 3$ \\
\hline P14 & Actual piles & Solid & Non-linear & 1.0 & 42 & 2.8 & Design & $2.25 \times 2.25$ \\
\hline P15 & Actual piles & Solid & Non-linear & 1.0 & 42 & 2.8 & Design & $1.50 \times 1.50$ \\
\hline P16 & Actual piles & Solid & Non-linear & 1.0 & 42 & 2.8 & Design & $0.75 \times 0.75$ \\
\hline
\end{tabular}

\subsection{Concrete material model}

For concrete, the fracture-plastic constitutive material model, CC3DNonLinCementitious2, was used, which is available in ATENA-3D software. The model includes for both non-linear of compressive and tensile behavior of concrete according to fib model code for concrete structures (MC10. CEB-FIP Model Code 2010). The uniaxial stress-strain relationship of the concrete is shown in Figure 5. For tension after cracking, a fictitious crack model is used which is based on a crack-opening law and fracture energy. More details can be found in ATENA Theory (Cervenka et al. 2002). The function of crack opening based on the exponential function experimentally derived by Hordijk 1991 was utilized.
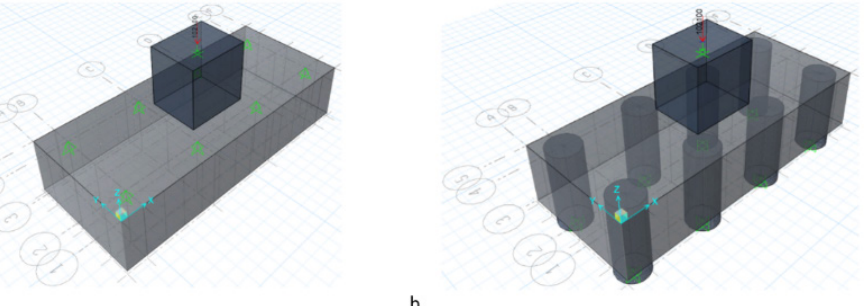

Figure 2 Plate element model a) pin supports (P1) and b) actual piles (P2) 

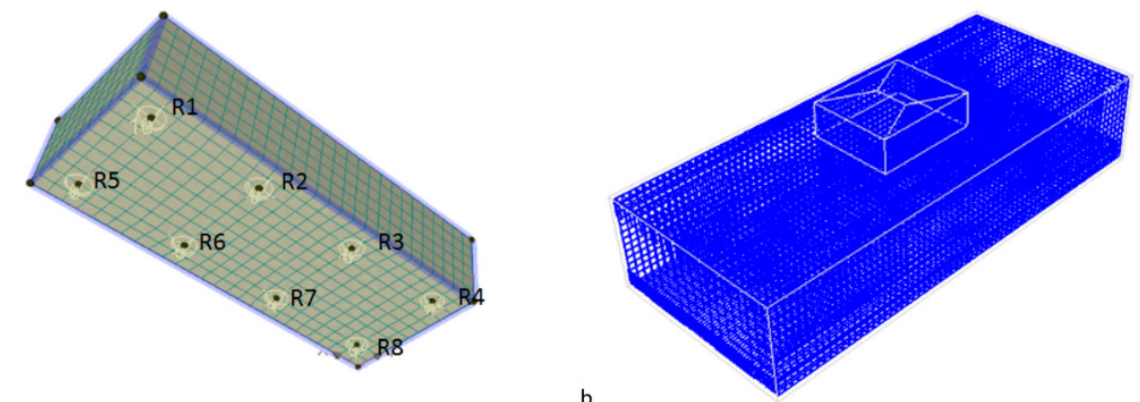

Figure 3 Finite element model of P3 a) finite element model and b) steel bars
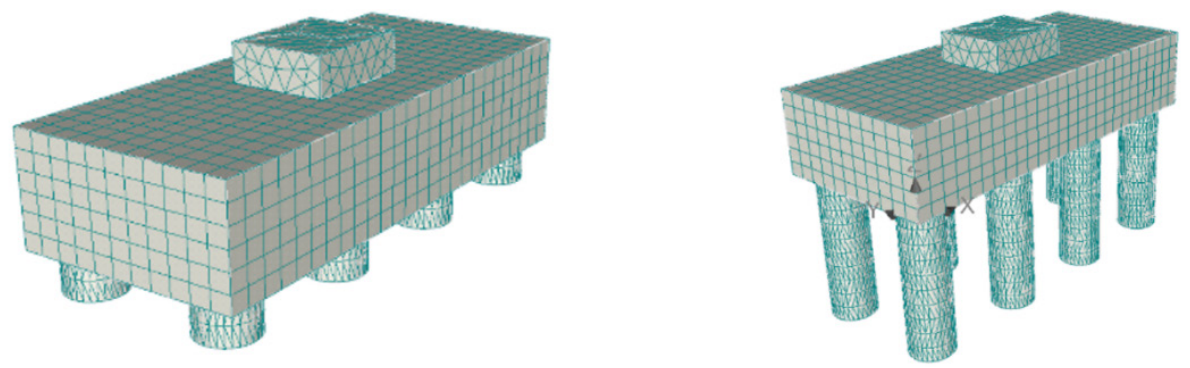

a

b

Figure 4 Finite element models of a) P4 and b) P7

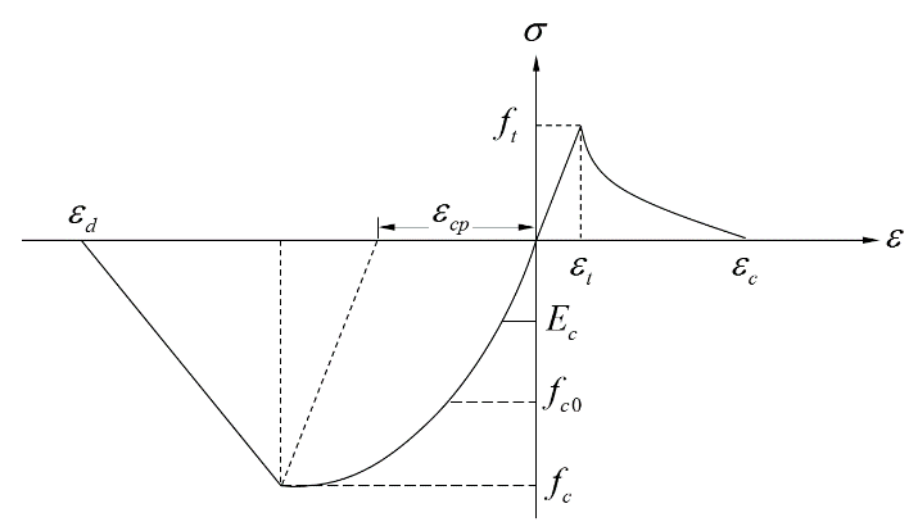

Figure 5 Uniaxial stress-strain relationship of concrete in ATENA-3D

$\frac{\sigma}{f_{t}}=\left\{1+\left(c \frac{w}{w_{c}}\right)^{3}\right\} \exp \left(-c_{2} \frac{w}{w_{c}}\right)-\frac{w}{w_{c}}\left(1+c_{1}^{3}\right) \exp \left(-c^{2}\right)$

where ${ }^{c_{1}}$ is a constant equal to 3

$c_{2}$ is a constant equal to 6.93

$w$ is the crack width (m.)

$w_{c}$ is the crack opening at the complete release of stress (m.)

$G_{f}$ is the fracture energy $\left(\mathrm{Nm} / \mathrm{m}^{2}\right)$

$f_{t}$ is the concrete tensile strength (MPa)

$w_{c}=5.4 \frac{G_{f}}{f_{t}}$ 
The fracture model of CC3DNonLinCementitious2 is also combined with an orthotropic smeared crack formulation and crack band model. The crack width is computed by multiplying the summation of the total value of fracturing strain and current increment fracturing strain, with the characteristic length, Lt. This characteristic length is called the "crack band width". It represents the length of the over element which the crack is distributed. A schematic represents the above exponential function and the crack band width of a finite element is illustrated in Figure 6.

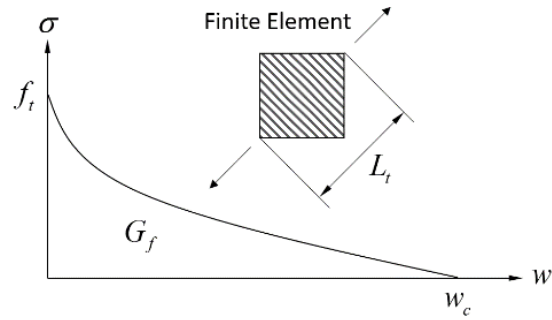

Figure 6 Tensile softening function and crack band width utilized in ATENA

For tri-axial stress failure criterion, two models are combined for different behavior of concrete in a tri-axial state of stress; 1) cracking Figure 7a of concrete by Rankine failure criterion and 2) plasticity model based on Menétrey and Willam 1995 failure criterion. Thus, two input parameters are involved. One is the shape of the failure envelope, which is dependent on an eccentricity factor, $e$. If the eccentricity is equal to 0.5 , the failure envelopes the form of a triangle. A circular form is enveloped if the eccentricity is equal to 1 . Another parameter is the return direction, $\beta$ in which the predictor state of stress returns to the failure envelope. In ATENA, the value of $\beta$ is used for determining the return direction. It depends on how material behaves when crushed. If $\beta$ is less than 0 , the material is being compacted during crushing, if $\beta$ is equal to 0 , the material volume is preserved and if $\beta$ is greater than 0 , the material is dilating. More comprehensive details and other parameters for calibrating the model can be found more in ATENA theory (Cervenka et al. 2002). Failure criterion for tri-axial states of stress and plastic predictor is depicted in Figure $7 \mathrm{~b}$.

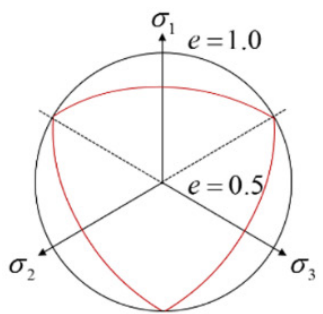

(a)

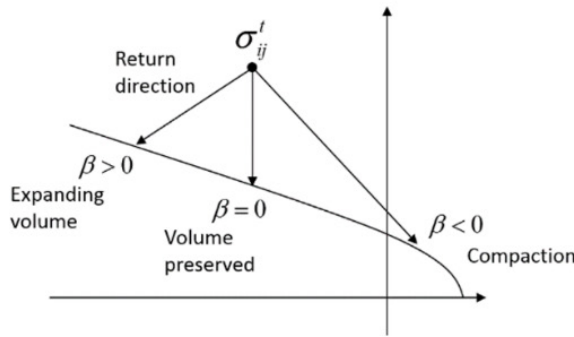

(b)

Figure 7 Surface shape of failure criterion for tri-axial states of stress and plastic predictor

Based on this study, a detailed calibration scheme for the constitutive model of concrete can be summarized in Table 2.

Table 2 Parameters for constitutive concrete model

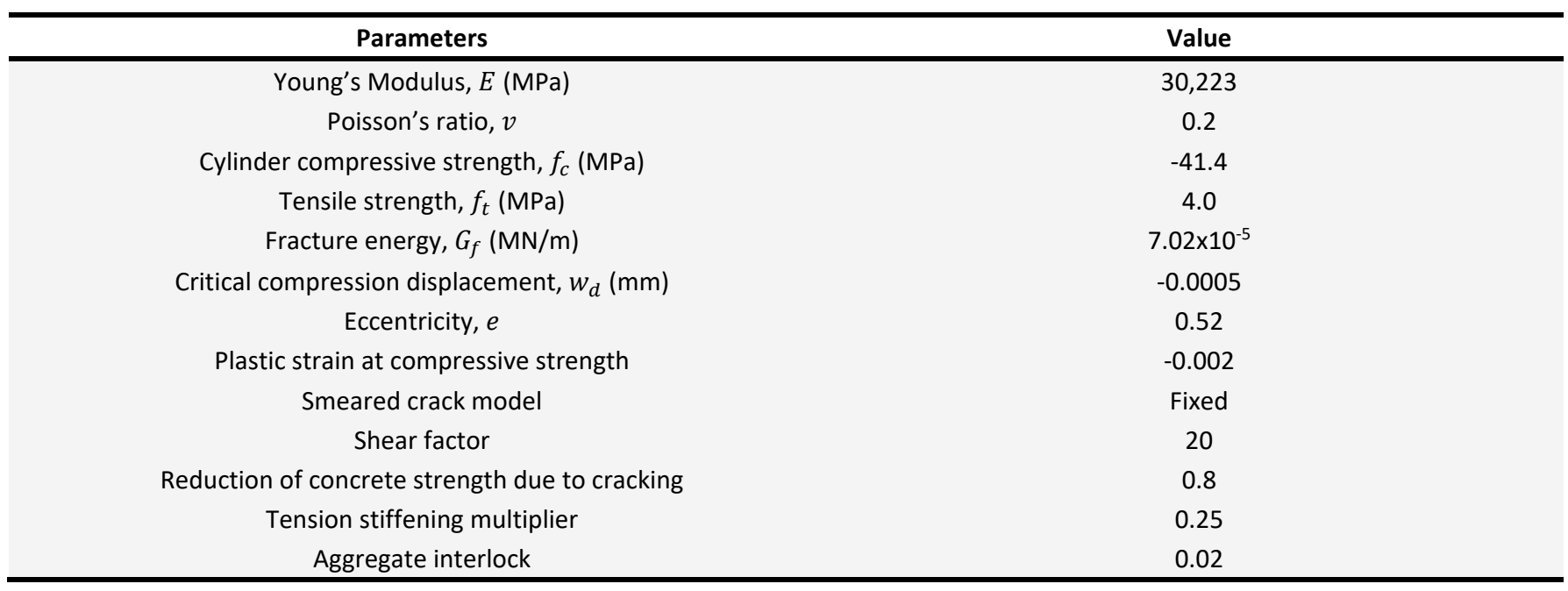




\subsection{Constitutive model of reinforcement}

1D truss element was used for the reinforcement bars in this model. The material properties were assigned using CCReinforcement material mode, which is also available in ATENA-3D. All reinforcement bars were modelled with an assumption of perfect bond to concrete element. A multi-linear plastic stress-strain relationship of reinforcement bars is shown in Figure 8. In this study, buckling of longitudinal steel bars were not considered and steel bars in the compression and tension zone were modelled using same constitutive model as shown in Figure 8.

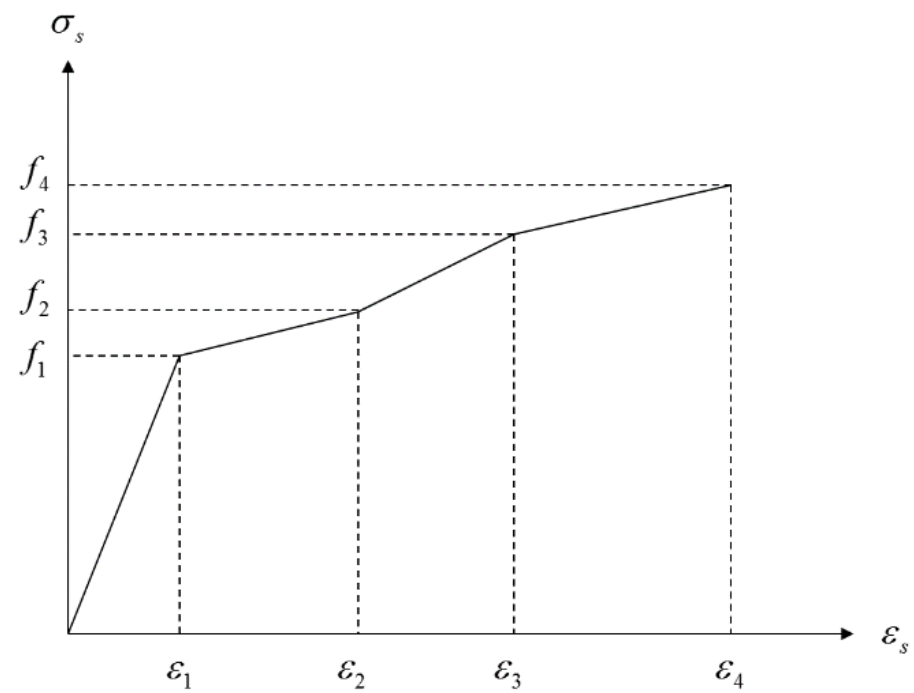

Figure 8 Constitutive model for reinforcement

\subsection{FINITE ELEMENT ANALYSIS RESULTS}

The finite element analysis results are briefly discussed in the following sections.

\subsection{Effect of support conditions}

Almost all types of finite element analysis tools such as ATENA, ETAB and SAP provide different support or restraint conditions such as roller, pin or fixed. The finite element analysis of RC pile caps could be performed either by using pin support or by modelling actual piles in the computer program ATENA. In this study, it was proposed to simulate the effect of support conditions by considering both pin support and actual piles. For this purposes, four finite element models $\mathrm{P} 1$, P2, P3, P4, were developed and analyzed linearly. In the finite element models P1 and P2, the element type was plate, whereas, in the finite element models, P3 and P4 element type was solid. Also, the finite element models P5 and P6 were analyzed non-linearly to study the effect of support conditions. The finite element analysis results were accessed in the form of pile or pin reactions R1-R8 as shown in Figure 2a. The finite element analysis results are given in Table 3 and shown in Figures 9-11. The theoretical calculations by using conventional method are also given in Table 3 and Figures 9-11. The calculation by using conventional method illustrates equal reactions at all supports as shown in Figures 9-11 and Table 3. Whereas, the finite element analysis (linear analysis) indicates that behavior of RC pile cap is not purely rigid and resulting reactions are not equal at each pile for both support conditions i.e., pin support and actual piles. Further it is evident that in the case of pin supports, there are negative values for support reactions R1, R4, R5 and R8. Whereas, in the case of actual piles all reactions are observed positive. In general, the calculated reactions of finite element model P2 are higher than the finite element model P1 as shown in Figure 9. It can be also see in the Figure 9 that reactions of finite element model P1 are close to the theoretical calculations at all locations. In case of finite element model P2, the divergence between the finite element analysis curve and the theoretical values is larger than the finite element model $\mathrm{P1}$. Further in the case of solid elements for RC pile cap in linear analysis, the calculated reactions are found positive for both types of support conditions such as pin and actual piles as shown in Figure 10. Similar to the plate element, the calculated reactions of finite element model P4 are higher than the finite element model P3 due to the presence of actual piles. The divergence between the finite element analysis curves of both models (P3 and P4) and the theoretical values is almost same at all locations. Further, in the case of non-linear analysis, the comparison between finite elements $\mathrm{P} 5$ and $\mathrm{P} 6$ is shown in Figure 11. The calculations based on rigid body assumption are also shown in Figure 11. It can be seen that type of support had a significant effect on the overall behavior of RC pile cap. In the case of pile support, highest 
reactions are observed at the middle, whereas, lowest values of reactions are observed at the ends of RC pile cap, indicating that RC pile cap is not purely rigid under applied load. In case of pin support, the behavior of RC pile cap P5 is similar to the pile cap P6, however, finite element analysis reactions are close to the calculations. In case of finite element model P6, the divergence between the finite element analysis curve and the theoretical values is much larger than the finite element model P5.

Table 3 Finite element analysis results

\begin{tabular}{|c|c|c|c|c|c|c|c|}
\hline Reactions & $\begin{array}{c}\text { Calculations } \\
(\mathbf{k N})\end{array}$ & P1 & $\mathbf{P 2}$ & P3 & P4 & P5 & P6 \\
\hline $\mathrm{R} 1$ & 12,763 & -1814 & 3,132 & 5,122 & 3,910 & 8,694 & 3,003 \\
\hline $\mathrm{R} 2$ & 12,763 & 27,339 & 22,392 & 20,400 & 21,620 & 15,620 & 21,950 \\
\hline R3 & 12,763 & 27,339 & 22,392 & 20,400 & 21,630 & 13,790 & 21,690 \\
\hline R4 & 12,763 & $-1,814$ & 3,132 & 5,124 & 3,895 & 9,077 & 2,902 \\
\hline R5 & 12,763 & $-1,814$ & 3,132 & 5,136 & 3,905 & 8,863 & 2,758 \\
\hline R6 & 12,763 & 27,339 & 22,392 & 20,390 & 21,600 & 14,700 & 22,130 \\
\hline R7 & 12,763 & 27,339 & 22,392 & 20,390 & 21,640 & 14,780 & 21,960 \\
\hline R8 & 12,763 & $-1,814$ & 3,132 & 5,135 & 3,905 & 8,989 & 2,913 \\
\hline Summation & $102,100.0$ & 102,100 & 102,096 & 102,097 & 102,105 & 94,513 & 99,306 \\
\hline
\end{tabular}

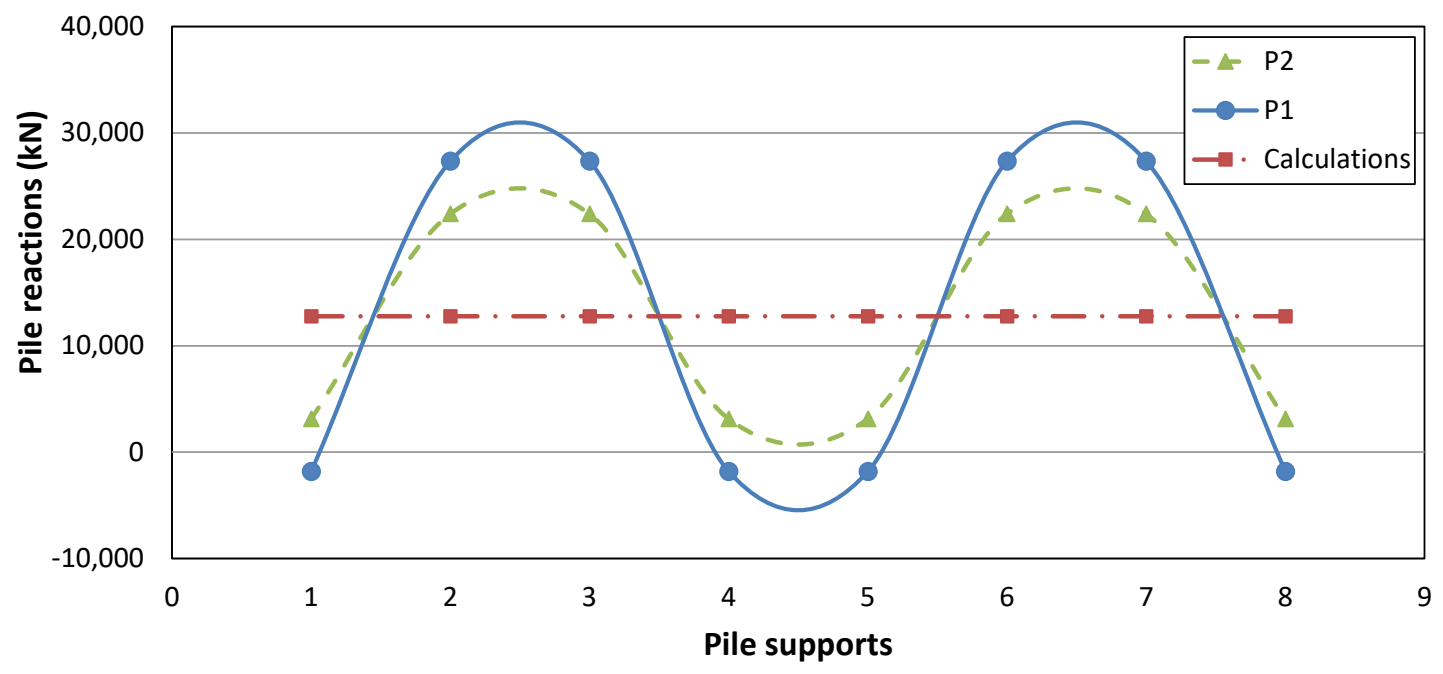

Figure 9 Comparison of reactions (Finite element models P1 and P2)

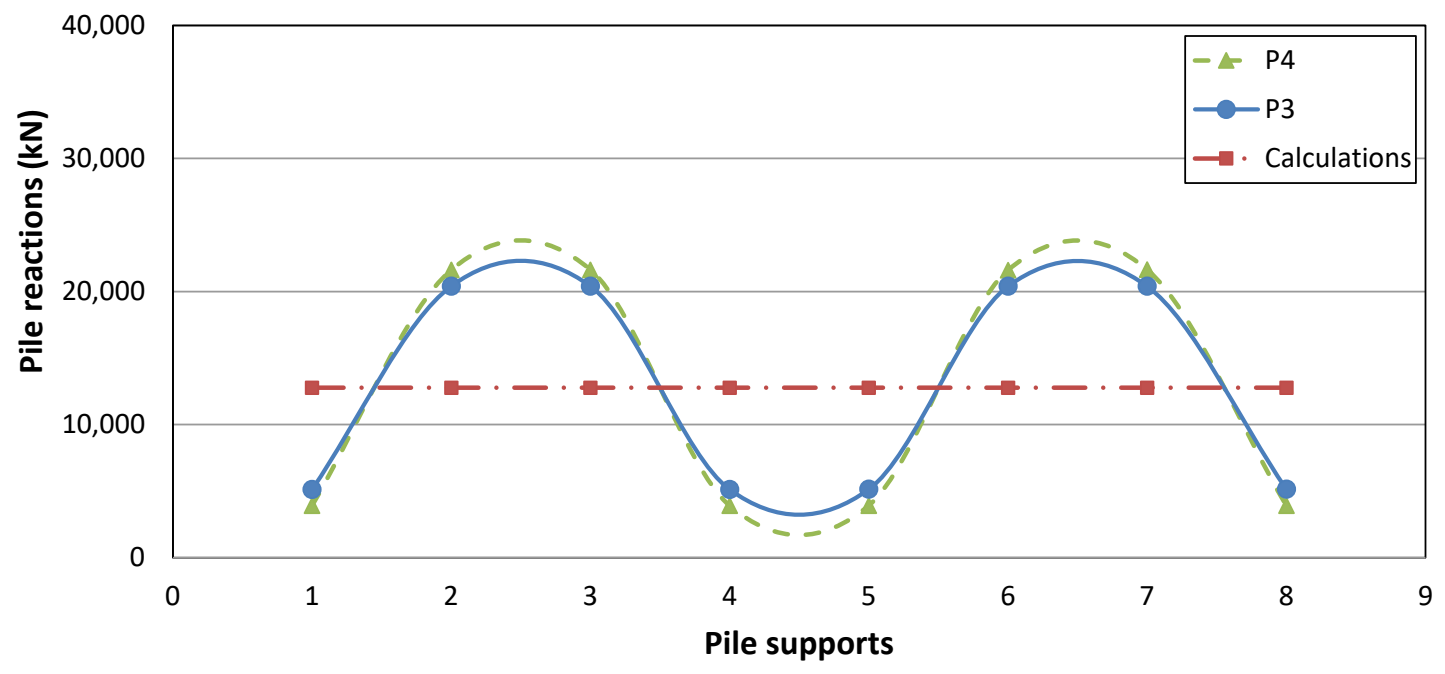

Figure 10 Comparison of reactions (Finite element models P3 and P4) 


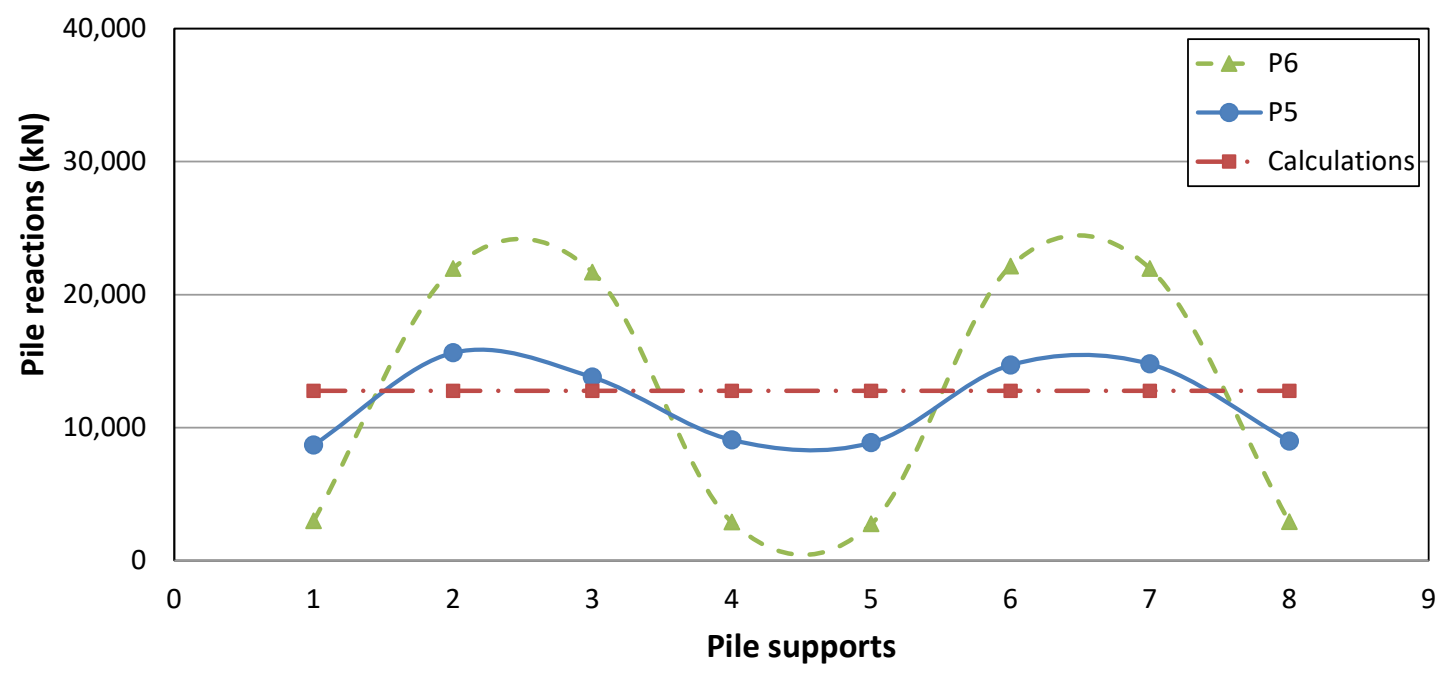

Figure 11 Comparison of reactions (Finite element models P5 and P6)

\subsection{Effect of analysis type}

In this study, two different types of analysis conditions such as linear analysis and non-linear analysis were employed to simulate the structural behavior of RC eight-pile cap. Analysis conditions were considered for both types of support conditions such as pin support and actual piles. For this purpose, analysis results of finite element model P3 are compared with the finite element model P5 and analysis results of finite element models P4 are compared with the finite element model P6 in Figures 12 and 13, respectively. Finite element analysis results are also summarized in Table 3. It can be seen that type of analysis had a significant effect on overall behavior of RC pile cap in the case of pin supports. The reactions of finite element model P3 are found higher than the finite element model P1 at middle of RC pile cap (i.e., R2, R3, R6 and R7). However, the reactions of finite element model P3 are found lower than the finite element model P5 at edges and middle location as shown in Figure 12. Further, in the case of finite element model P5, the divergence between the finite element analysis curve and the theoretical values is much larger than the finite element model P3. In contrast to the pin supports, it was observed that analysis type had insignificant effect on the reactions when actual piles were considered in the analysis. In the case of pile supports, the reactions in both cases i.e., P4 and P6 are found close to each other as shown in Figure 13. In general, the behavior of all finite element models was not purely rigid with different reactions at each support. Also, the finite element analysis results are found higher than the calculated values at the mid location and lower at the end locations as shown in Figure 13.

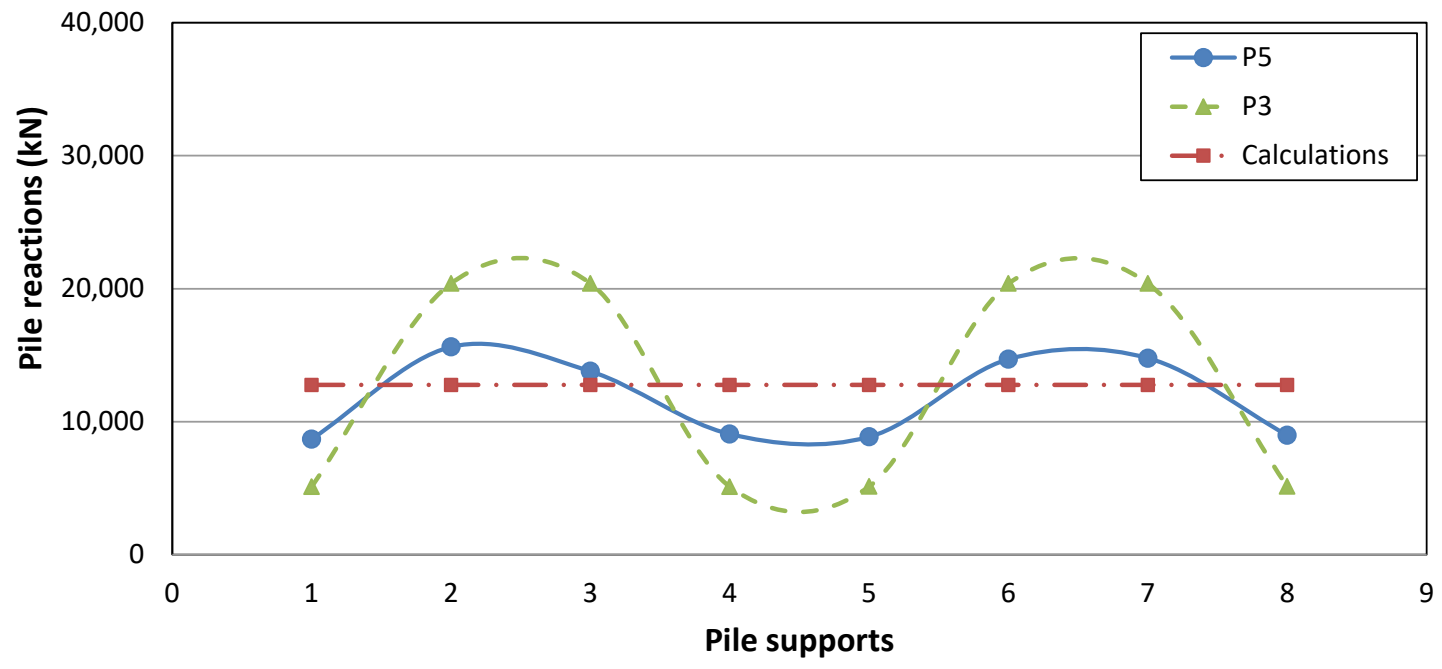

Figure 12 Comparison of reactions (Finite element models P3 and P5) 


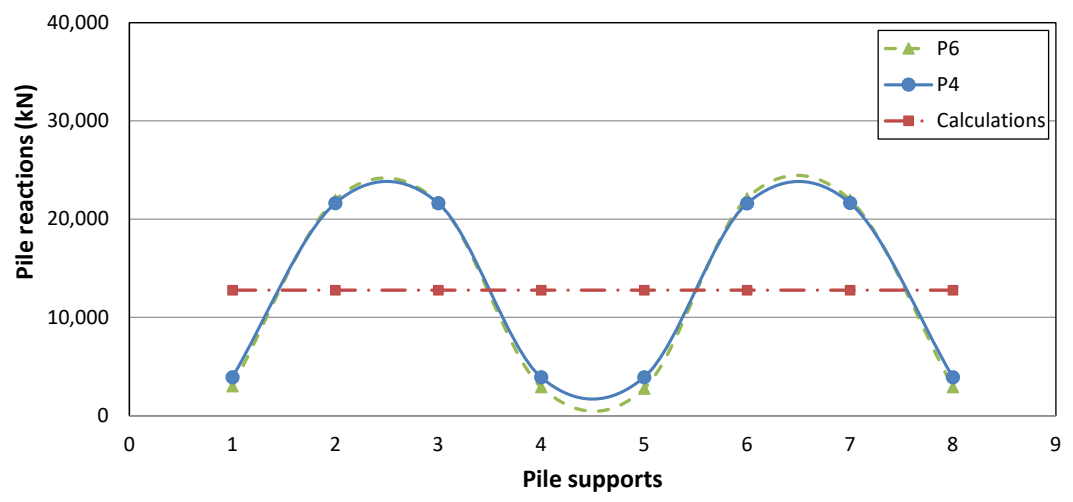

Figure 13 Comparison of reactions (Finite element models P4 and P6)

\subsection{Effect of pile length}

In actual construction, RC pile caps are constructed with different pile lengths. In this study, three types of pile lengths i.e., 1, 5 and $10 \mathrm{~m}$ were considered and their effect on structural behavior of RC pile cap is simulated. The finite element models P6, P7 and P8 were developed with pile lengths 1, 5 and 10 meter respectively. In all finite element models, RC pile cap was modelled using solid element and analysis was carried out in non-linear way. The finite element analysis results are summarized in Table 4 and comparison of finite element analysis results is shown in Figure 14. It can be seen that length of pile had a significant effect on the structural response of RC pile cap. In general, the behavior of all pile caps irrespective of pile length is non-rigid, highest reactions are observed at the mid location and lowest values are observed at the ends. The divergence between the finite element analysis curves of models (P7 and P8) and the theoretical values is almost same at all locations and higher than the finite element model P6 as shown in figure 14. Further, it can be seen that with an increase in the pile length, there is a reduction in the reactions at the ends and increment in the reactions at mid location. This phenomenon indicates that piles wither higher lengths result in higher stiffness and rigidity than piles with shorter lengths.

Table 4 Finite element analysis results (effect of analysis type)

\begin{tabular}{ccccc}
\hline Pile reactions & $\begin{array}{c}\text { Conventional method } \\
(\mathbf{k N})\end{array}$ & P6 & P7 & P8 \\
\hline R1 & 12,763 & 3,003 & 3,904 & 5,082 \\
R2 & 12,763 & 21,950 & 17,990 & 18,060 \\
R3 & 12,763 & 21,690 & 17,550 & 17,830 \\
R4 & 12,763 & 2,902 & 3,923 & 5,185 \\
R5 & 12,763 & 2,758 & 4,438 & 5,439 \\
R6 & 12,763 & 22,130 & 16,890 & 17,520 \\
R7 & 12,763 & 21,960 & 17,540 & 17,530 \\
R8 & 12,763 & 2,913 & 4,286 & 5,391 \\
Summation & $102,100.0$ & 99,306 & 86,521 & 92,037 \\
\hline
\end{tabular}

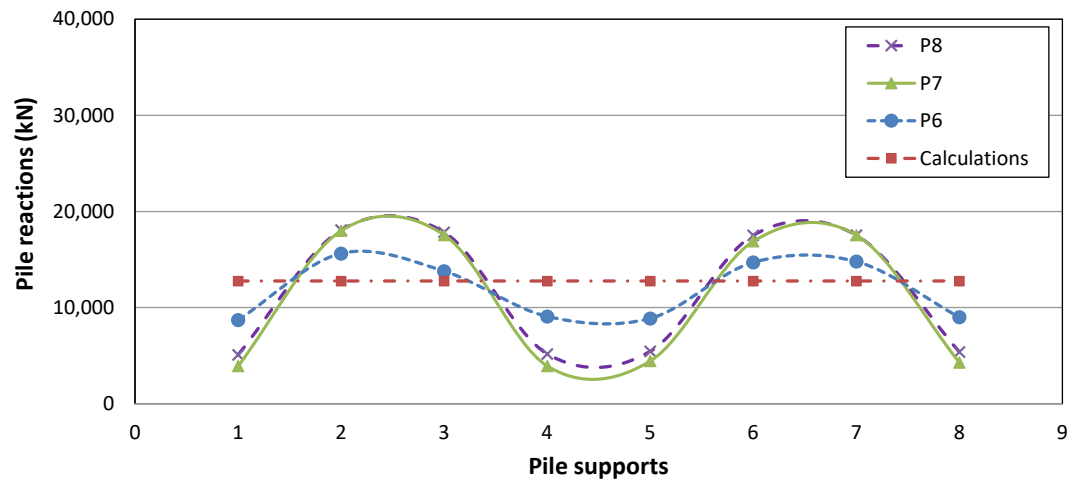

Figure 14 Comparison of reactions (Finite element models P6, P7 and P8) 


\subsection{Effect of strength of concrete}

Similar to the pile length, in actual construction, concrete of different strengths is employed to for the construction of RC pile caps and to safely transfer load from super structure to the piles. In this study, three different types of concrete strengths $42 \mathrm{MPa}, 60 \mathrm{MPa}$ and $80 \mathrm{MPa}$ were considered in finite element models $\mathrm{P} 4, \mathrm{P} 9$ and $\mathrm{P} 10$, respectively. Other parameters such as type of support, element, analysis and length of pile were kept constant. Analysis results are graphically shown in Figure 15 and summarized in Table 5, along with theoretical calculations. Although there is found slight effect of concrete strength on reactions at end locations of RC pile cap. In general, it can be concluded that strength of concrete had insignificant effect on the structural response of RC pile cap in terms of resulting reactions as shown in Figure 15. The divergence between the finite element analysis curves of models (P9 and P10) and the theoretical values is almost same at all locations and higher than the finite element model P6 as shown in figure 14.

\subsection{Effect of thickness of pile cap}

In this study, the effect of thickness of RC pile cap was also considered to simulate the effect of pile thickness on structural behavior of RC pile caps. The selected pile thicknesses were $2.8 \mathrm{~m}, 4.0 \mathrm{~m}$ and 5.2 meter and their respective finite element models are P4, P11 and P12, respectively. All other research parameters such as type of support, element type, and analysis type, length of pile and strength of concrete were kept constant. Analysis results are graphically shown in Figure 16 and summarized in Table 5, along with theoretical calculations. It can be seen that the thickness of RC pile cap had a significant effect on the structural behavior of RC pile caps both in terms of reactions and rigidity. In general, the behavior of all finite element models was not purely rigid with different reactions at each support. Also, the finite element analysis results are found higher than the calculated values at the mid location and lower at the end locations as shown in Figure 16. The RC pile cap with thickness $2.8 \mathrm{~m}$ (i.e., P6) is observed as more flexible and non-rigid than RC pile caps P11 and P12. The RC pile cap with thickness $5.2 \mathrm{~m}$ is observed more rigid and observed reactions are observed quite close to the theoretical calculations. This phenomenon indicates that assumption of rigid body pile cap is only valid for very large thickness of RC pile cap.

Table 5 Finite element analysis results (effect of analysis type)

\begin{tabular}{cccccc}
\hline Pile reactions & $\begin{array}{c}\text { Conventional } \\
\text { method (kN) }\end{array}$ & P9 & P10 & P11 & P12 \\
\hline R1 & 12,763 & 3,873 & 3,748 & 7,223 & 11,360 \\
R2 & 12,763 & 21,660 & 21,780 & 18,300 & 14,160 \\
R3 & 12,763 & 21,660 & 21,790 & 18,310 & 14,170 \\
R4 & 12,763 & 3,857 & 3,731 & 7,214 & 11,360 \\
R5 & 12,763 & 3,868 & 3,741 & 7,222 & 11,360 \\
R6 & 12,763 & 21,640 & 21,760 & 18,290 & 14,160 \\
R7 & 12,763 & 21,670 & 21,800 & 18,320 & 14,170 \\
R8 & 12,763 & 3,868 & 3,742 & 7,219 & 11,360 \\
Summation & $102,100.0$ & 102,096 & 102,092 & 102,098 & 102,100 \\
\hline
\end{tabular}

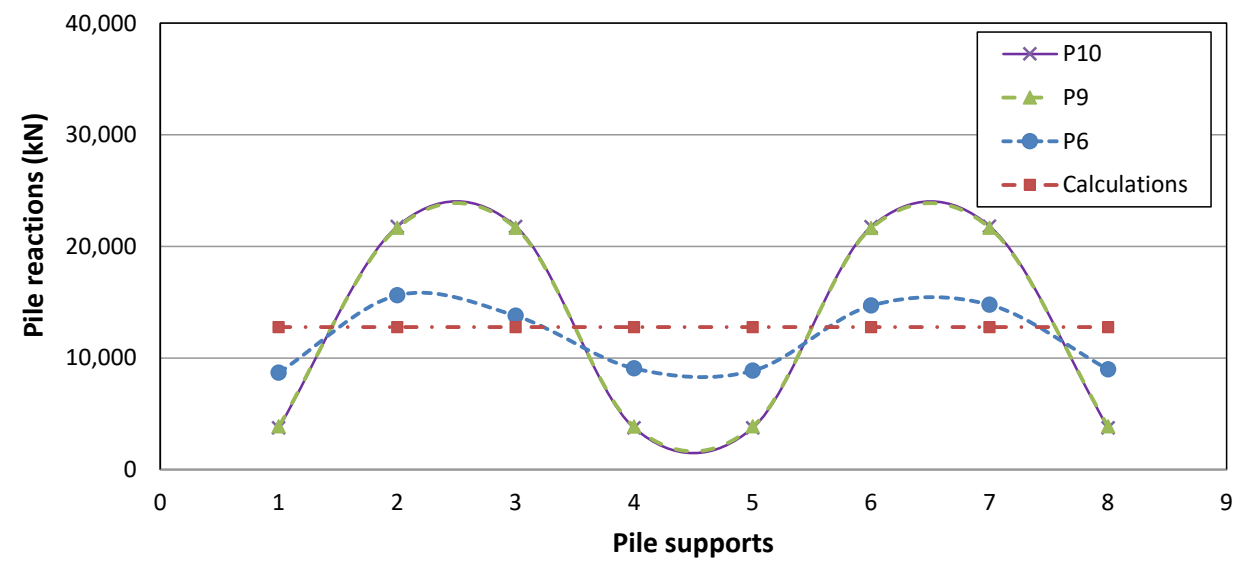

Figure 15 Comparison of reactions (Finite element models P6, P9 and P10) 


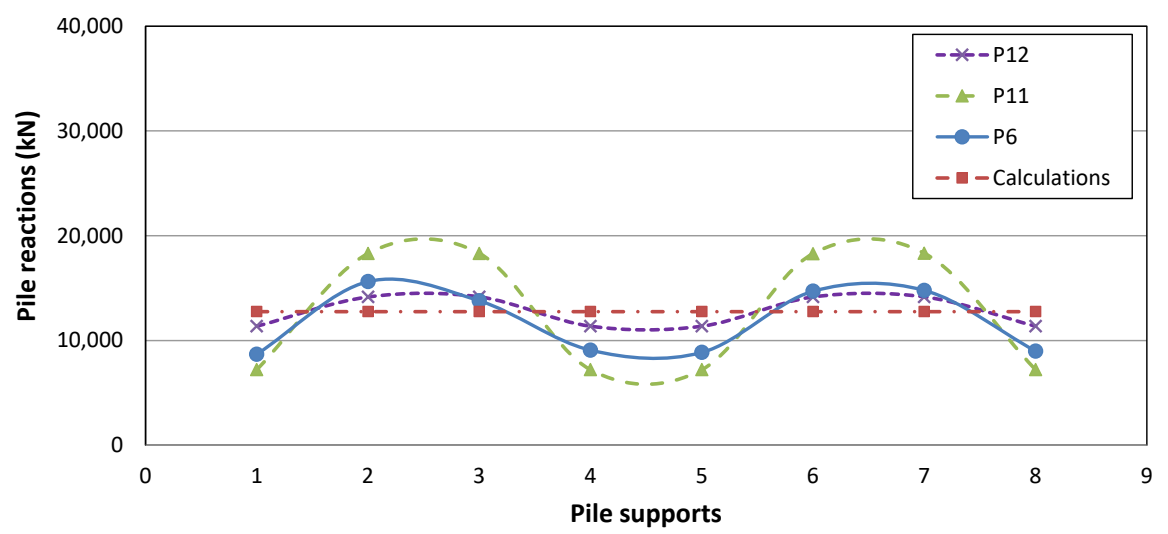

Figure 16 Comparison of reactions (Finite element models P6, P11 and P12)

\subsection{Effect of loading conditions}

In this study, two types of loading conditions such as service and design load conditions were considered in the finite element models P6 and P13, respectively. In the service load condition, maximum applied load was equal to $41707 \mathrm{kN}$ and in the ultimate load condition, maximum applied load was equal to $102100 \mathrm{kN}$. The analysis results of both models are summarized in Table 5 and shown in Figure 17. Under service load and pile cap self-weight, there are tensile crack $0.1 \mathrm{~mm}$ width at bottom face of pile cap under the pier along transverse direction. However, the crack width is lower than guide to reasonable crack width ( $\mathrm{ACl} 2001$ ), suggested should be less than $0.3 \mathrm{~mm}$. for humidity, moist air and soil exposure condition. The average pile reaction located near the pier (R2, R3, R6 and R7) is $9750 \mathrm{kN}$ and $9028 \mathrm{kN}$ for nonlinear and linear analysis, respectively. The reaction $(R)$ is greater than rigid body assumption, $5853 \mathrm{kN}$ and pile safe load, $8829 \mathrm{kN}$ per pile. However, the average pile reaction located far from pier (R1, R4, R5 and R8) show the lower value, $1931 \mathrm{kN}$ and $2440 \mathrm{kN}$, for non-linear and linear analysis, respectively. The principal compressive stress is $10 \mathrm{MPa}$ at the area around the pier which is less than allowable stress for both linear and non-linear analysis. The principal tensile stress is $6.3 \mathrm{MPa}$ at the bottom face of pile cap which is greater than tensile strength of concrete $4.0 \mathrm{MPa}$ and tensile crack was found at that location. The maximum tensile stress in steel is $28 \mathrm{MPa}$ for nonlinear analysis at longitudinal and transverse direction under the pier. However, the maximum tensile stress is lower and far from allowable tensile stress $280 \mathrm{MPa}$. The response under design service load show that compressive stress in concrete and tensile stress in steel are safe except pile reactions are greater than pile safe load. Under design ultimate load, the average pile reaction located near the pier (R2, R3, R6 and R7) is $10380 \mathrm{kN}$ and the average pile reaction located far from pier (R1, R4, R5 and R8) show the lower value, $4384 \mathrm{kN}$ for nonlinear analysis. However, the reaction for rigid body assumption is $7656 \mathrm{kN}$. The principal compressive stress is $20 \mathrm{MPa}$ which is lower than ultimate compressive strength $41.4 \mathrm{MPa}$. The principal tensile stress in steel is $56 \mathrm{MPa}$ which is lower and far from yield strength of bar $560 \mathrm{MPa}$. This situation may come from, many steel reinforcement are provided in the bottom of pile cap. The design ultimate load is still small (approximately 54\%) when compared to the result of FEM model. Plot the relationship between pier load and strain in concrete and steel (Fig. 17) show that steel will reach yield strain $(0.0027 \mathrm{~mm} / \mathrm{mm})$ when the pier load is more than $10,200 \mathrm{kN}$. Therefore, steel reinforcement is in elastic range and do not develop yield stress when the pier load at design ultimate load.

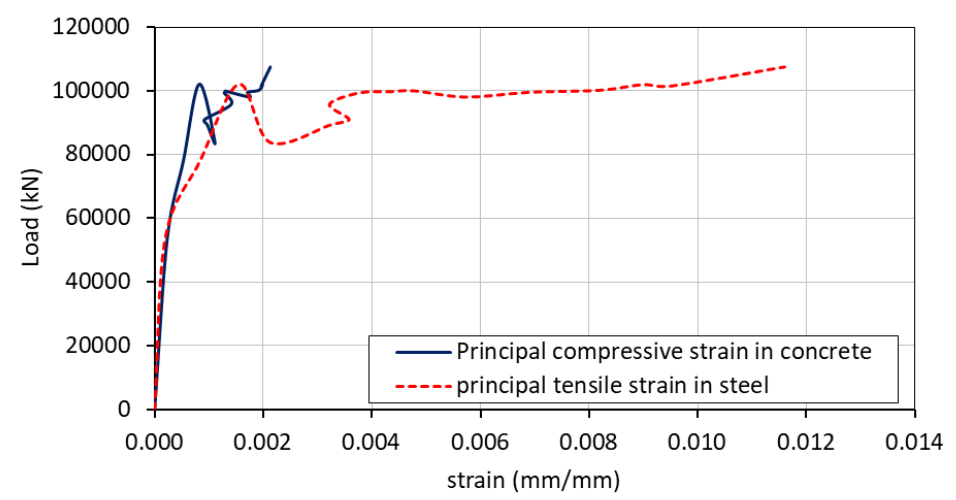

Figure 17 Relationship between pier load and compressive strain in concrete and tensile strain in steel 


\subsection{Effect of size of column on tensile stress of steel bars}

Three additional finite element models i.e., P14, P15 and P16 were developed in which size of column or pier was reduced by $25 \%, 50 \%$ and $75 \%$, respectively, to investigate the effect of size of column on the tensile stresses of longitudinal steel bars located at the tension zone of RC pile cap. The finite element analysis results of newly developed finite element models were compared with the finite element model P13. The analysis type was considered as non-linear and analysis was performed under ultimate loading conditions. The finite element analysis results in terms of maximum tensile stress are given in table 6 and distribution of tensile stresses on the longitudinal steel bars is shown in Figure 18. It can be seen that maximum tensile stress on longitudinal steel bars was increased as the column size was reduced. The maximum tensile stresses on longitudinal steel bars were increased by $83 \%, 139 \%$ and $223 \%$ as the area of column was reduced by $25 \%, 50 \%$ and $75 \%$, respectively. This phenomenon is related with the reduced moment arm in the case of small size columns.

Table 6 Finite element analysis results (effect of analysis type)

\begin{tabular}{ccc}
\hline Finite element models & Maximum tensile stress (MPa) & \% Increase in the tensile stress \\
\hline P13 & 56 \\
P14 & 103 \\
P15 & 134 \\
P16 & 181 \\
\hline
\end{tabular}

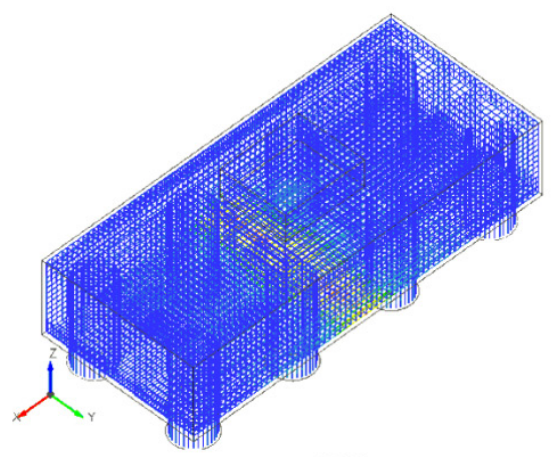

P13

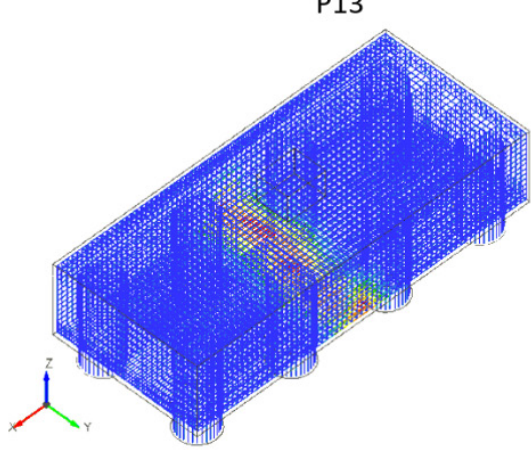

P15
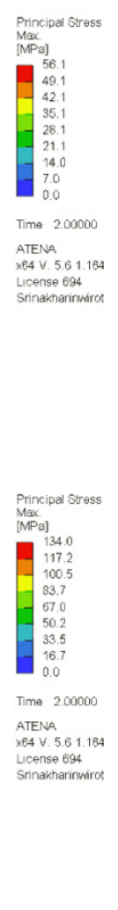

Figure 18 Distribution of tensile stresses on steel bars
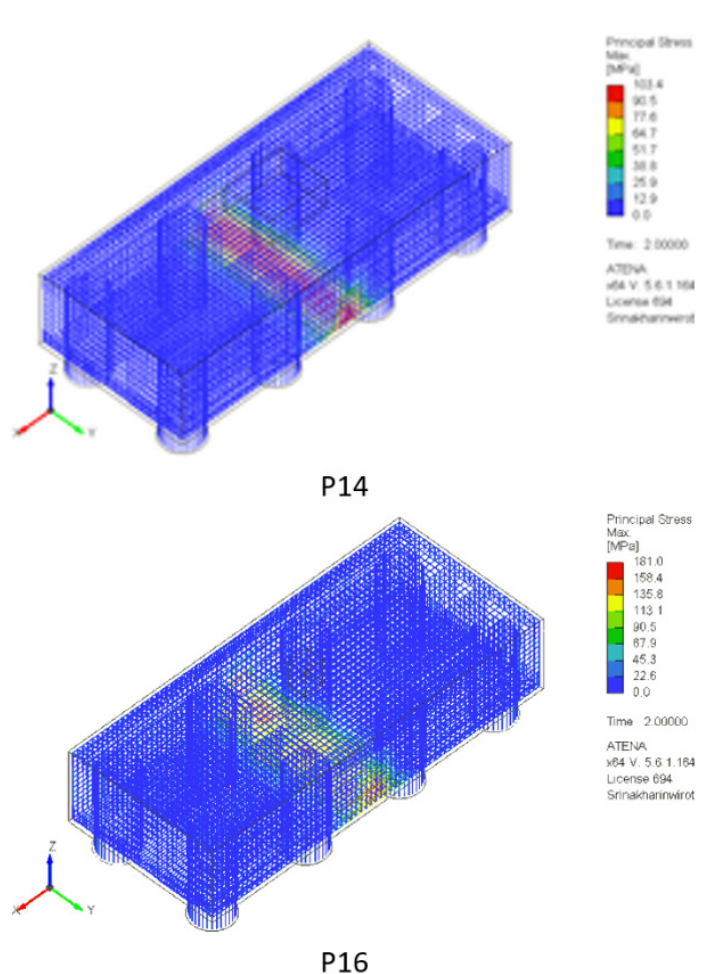

P16

\subsection{Distribution of Principal compressive stress}

In general the distribution of principal stresses was identical for all RC pile cap finite element models developed in this study. However, there was slight effect of support conditions i.e., pin supports and actual piles on the over distribution of principal compressive stresses of RC pile caps. The typical distribution of principal compressive stresses of finite element mode P1 (pin supports) and finite element model P2 (actual piles) are shown in Figures 19 and 20, respectively. It can be seen that the (Figure 19a and 20a) that initially stresses are mainly transferred from pier to the group of reactions or piles which are located near the pier in case of both pin supports and actual piles. The stress transfer is essentially inclined and angle of inclination is approximately 45 degree. The observed angle of inclination of stress transfer is in consistent with the existing studies. Previous studies indicate that angle of inclination of stress transfer from 
pier to piles is approximately 31-59 degree (Ingham et al. 2001). As the load was further increase, the stresses were also transferred to edge reactions and or piles as shown in Figures $19 \mathrm{~b}$ and $20 \mathrm{~b}$.
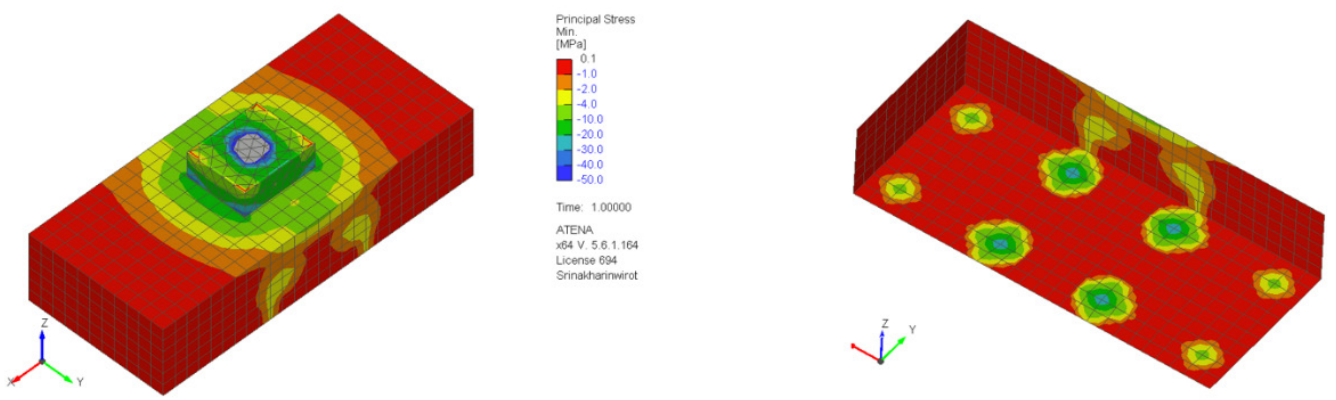

(a) Load $31900 \mathrm{kN}$ and deformation $4 \mathrm{~mm}$
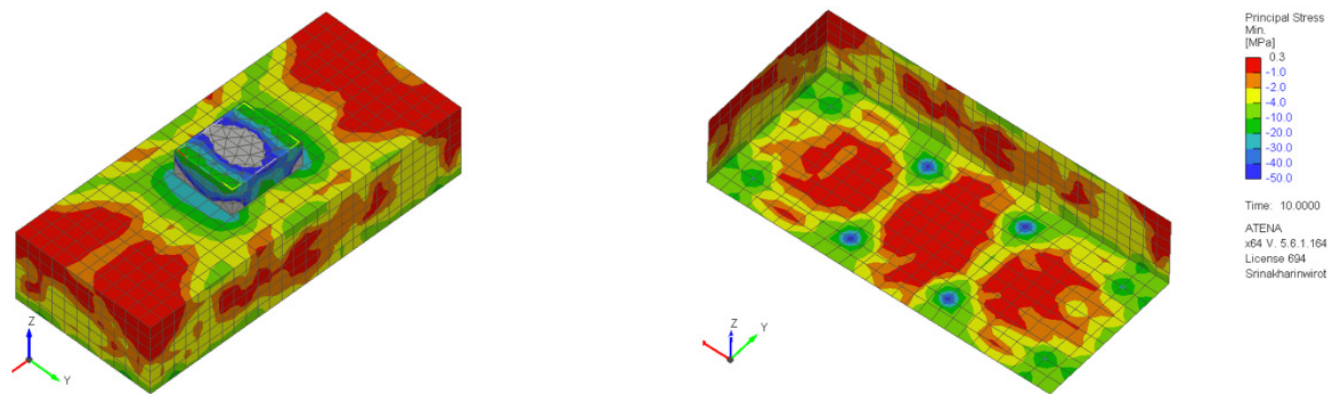

(b) Load $78140 \mathrm{kN}$ and deformation $120 \mathrm{~mm}$

Figure 19 Principal compressive stress of Finite element model P5
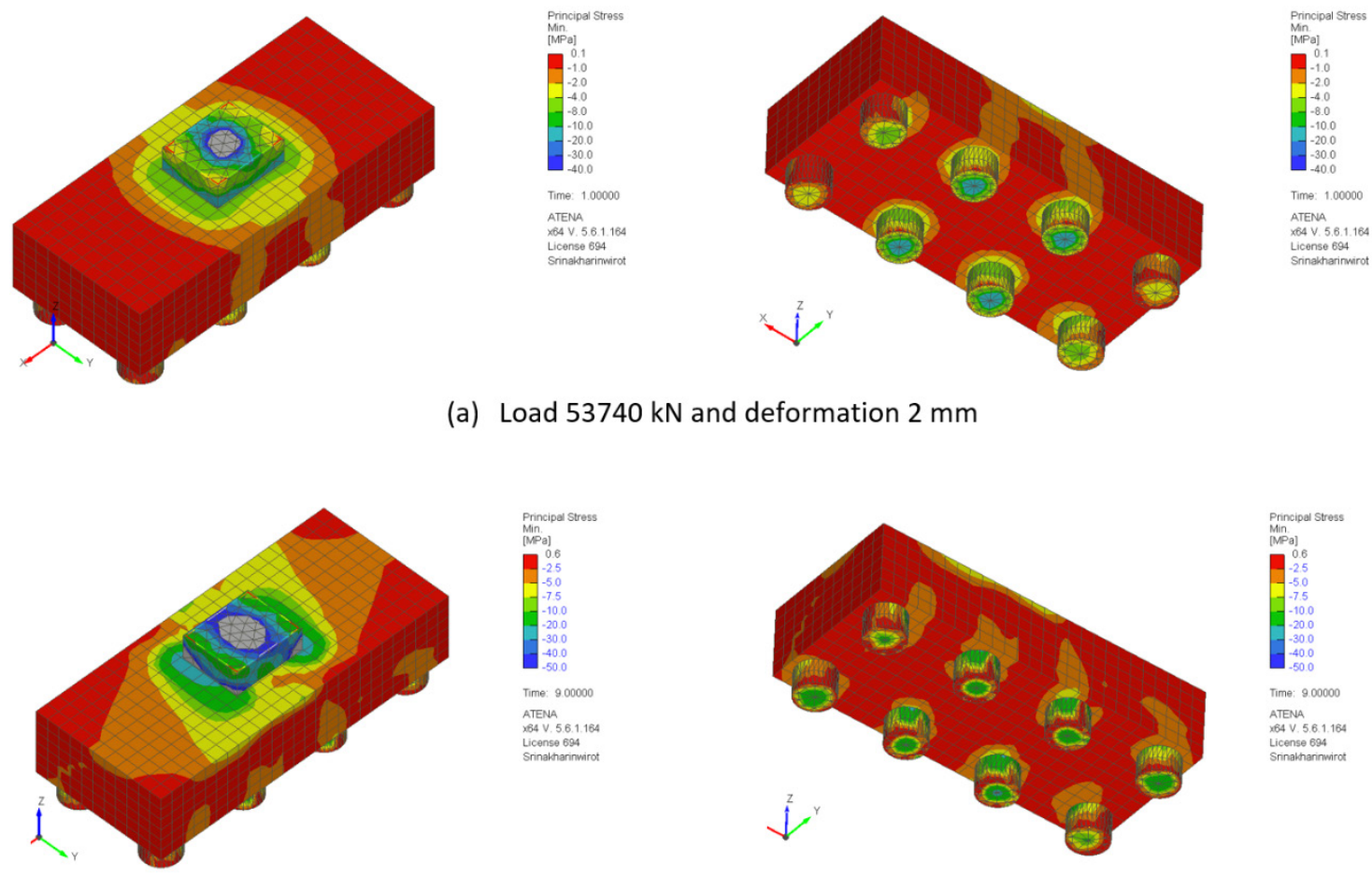

(b) Load 101,500 kN and deformation $40 \mathrm{~mm}$

Figure 20 Principal compressive stress of finite element model P6 


\subsection{Cracking pattern of finite element models}

Similar to the stress distribution, the crack initiation and propagation were also identical in all finite element models. There was slight difference in crack initiation and propagation in the case of pin supports and actual piles. The typical crack initiation and propagation is shown in figures 21 and 22 for finite element models P5 and P6, respectively. Initially i.e., at small deflections, few cracks were observed only at the tension side of RC pile caps as shown in Figures 21a and 22a. These cracks were mainly concentrated at the center of RC pile cap. As the load was further increased, vertical cracks were also observed in the RC pile cap at the location of interior or middle piles. With the further increase in the load, the crack width of the existing cracks was increased and also new cracks were observed over the full length of RC pile cap as shown in Figures $21 \mathrm{~b}$ and $22 \mathrm{~b}$. In general, more cracks were observed in the finite element model P5 as compared to the finite element model P6 for a particular deformation level i.e., $40 \mathrm{~mm}$ and at the ultimate stage, compression cracks were also noticed at the top of the RC pile cap as shown in Figures 21c and 22c.

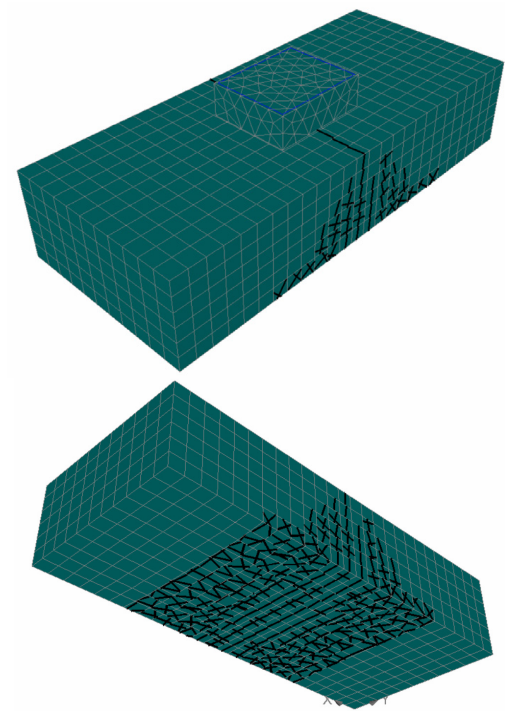

(a) Load $31,900 \mathrm{kN}$ and deformation $4 \mathrm{~mm}$

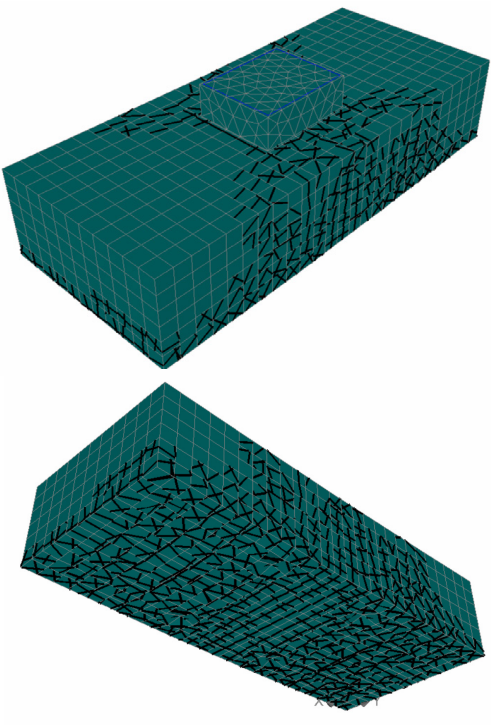

(b) Load 91,180 kN and deformation $20 \mathrm{~mm}$

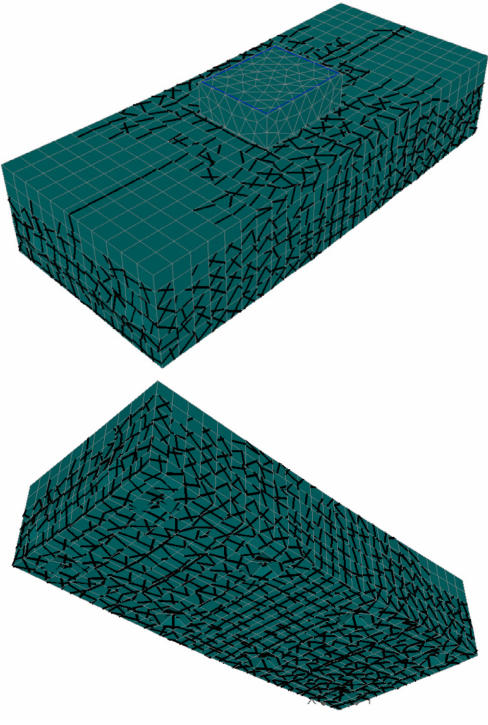

(c) Load $94,440 \mathrm{kN}$ and deformation $40 \mathrm{~mm}$

Figure $\mathbf{2 1}$ Crack prorogation of Finite element model P5

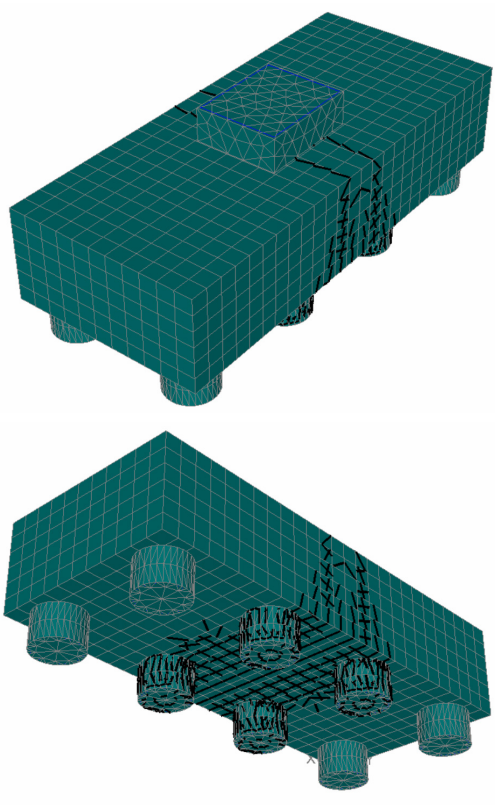

(a) Load $78,140 \mathrm{kN}$ and deformation $4 \mathrm{~mm}$

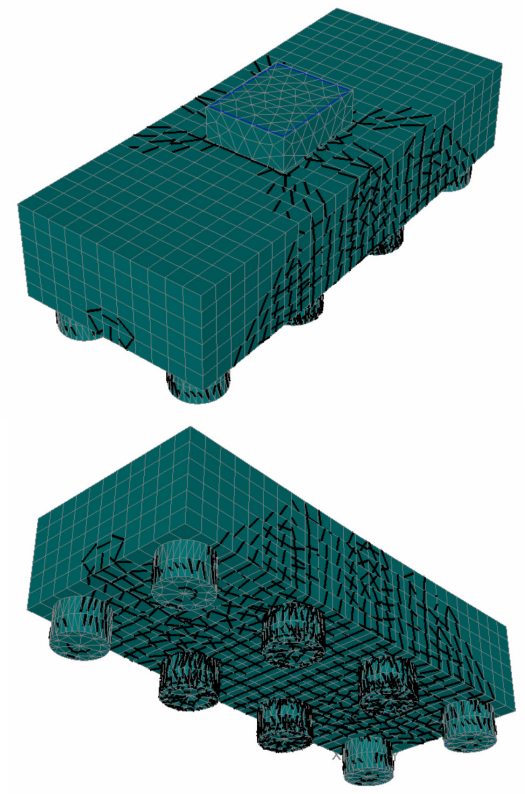

(b) Load 99,980 kN and deformation $20 \mathrm{~mm}$

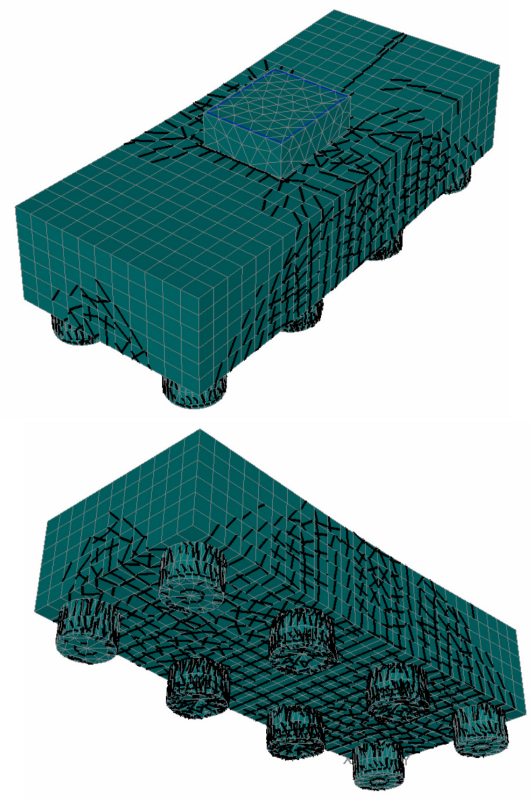

(c) Load 99,657 kN and deformation $40 \mathrm{~mm}$

Figure 22 Crack prorogation of Finite element model P6 


\section{CONCLUSIONS}

This study represents a detailed finite element analysis of RC eight-pile cap by using a computer program ATENA. ATENA serve as rational tools to explain the behavior of RC structures. Research parameters included different types of loading conditions, analysis types such as linear and non-linear, support conditions, length of pile, strength of concrete and thickness of pile cap. Based on finite element analysis results, following conclusions are drawn;

- Nonlinear and linear analysis also shown the same tendency that pile located near the pier can transfer higher reaction than that of the pile located far from the pier which different from the assumption of code practice which assumed equal pile reaction.

- The solid model for pile cap with and without pile can resist the same maximum pier load. However the model with pile cap is more realistic behavior even though linear or nonlinear analysis. The pile reaction ratio of linear to nonlinear analysis is between 0.98-1.42.

- The length of pile in the model with pile is effect to the maximum load of pier. When the length of pile is greater, the ability of pier load is reducer, due to slenderness ratio of pile. From the study, it reduce $9 \%$ and $13 \%$ when pile length increase from $1 \mathrm{~m}$ to $5 \mathrm{~m}$ and $5 \mathrm{~m}$ to $10 \mathrm{~m}$, respectively.

- Under linear analysis, increasing the compressive strength of concrete or increasing the modulus of elasticity of foundation only cannot increase rigidity behavior of pile cap. When increase thickness of the foundation to $12 \mathrm{~m}$ or 4.3 times of construction drawing thickness, the all pile reactions tend to be the same.

- The finite element analysis results indicate that the behavior of RC pile cap is not purely rigid and the distribution of forces on the RC piles is not uniform. More experimental and analytical studies are required to further verify these results and there is an urgent need to modify existing design guidelines of RC pile caps in which the behavior of RC pile caps is usually considered as rigid body.

\section{Acknowledgement}

The authors are indebted to the Faculty of Engineering, Srinakharinwirot University, and School of Engineering, University of Phayao (Unit of Excellence), for funding this research.

Author's Contribuitions: Writing - original draft, P Chaimahawan; Writing - review \& editing, S Suparp; Writing - review \& editing, P Joyklad; Writing - review \& editing, Q Hussain.

Editor: Marco L. Bittencourt.

\section{References}

Adebar, P., Kuchma, D., Collins, M. P. (1990). Strut-and-Tie Models for the Design of Pile Caps: An Experimental Study. ACIStructural Journal 87: 81-92.

Ahmed, S., Shah, A., Zaman, S. (2009). Evaluation of the Shear Strength of Four Pile Cap Using Strut and Tie Model (STM). Chinese Journal Institute of Eng. 32: 243-249.

Blévot, J.L., Frémy, R. (1967). Semelles sur Pieux. Institute Tech. du Bâtiment et des Travaux Publics 20(230): 223-295.

Cervenka, V., Jendele, L., Cervenka, J. (2005). ATENA Program Documentation - Part 1: Theory. Praha, Czech Rep.

Cervenka, V., Cervenka, J., Pukl, R. (2002). ATENA-A tool for engineering analysis of fracture in concrete. Sadhana 27(4): 485492.

Červenka, V., Jendele, L., \& Červenka, J. (2000). ATENA Program Documentation Part. Cervenka Consulting sro.

Clarke, J.L. (1973). Behavior and Design of Pile Caps with Four Piles (Sp. 1973). Tech. Report No. 42-489, Cement and Concrete Association, Wexham.

Hordijk, D.A. (1991). Local approach to fatigue of concrete. Thesis technische Universiteit Delft. W.D. Meinema b.v. Delft. 
Magade, S. B., Ingle, R. K. (2020). Comparison of Moments for Pile-Cap Design. Soil Mechanics and Foundation Engineering 56(6): 414-419.

MC10. CEB-FIP Model Code (2010). Bulletin d'Information No. 65/66. Comité Euro-International Du Béton.

Menétrey, P., Willam, K.J. (1995). Triaxial failure criterion for concrete and its generalization. ACI Structural Journal 92(3): 311318, 1995.

Mello, A. F. A. D., Souza, R. A. D. (2016). Analysis and design of reinforced concrete deep beams by a manual approach of stringer-panel method. Latin American Journal of Solids and Structures 13(6): 1126-1151.

N.H.T., Ingham J. M. Sritharan S. (2001), Monotonic non-linear strut and tie computer models. New Zealand National Society for Earthquake Engineering Bullentin, 34(3): 169-190.

Park,J., Kuchma,D.A., Souza,R.A. (2008). Strength Predictions of Pile Caps by a Strut-and-Tie Model Approach. Canadian Journal of Civil Engineering 35(12): 1399-1413.

Sabnis, G. M., Gogate, A. B. (1984). Investigation of Thick Slabs (Pile Caps). ACI Structural Journal, Proceedings, 81(1): $35-39$.

Sam, C., Iyer, P. K. (1995). Nonlinear finite element analysis of reinforced concrete four-pile caps. Computers \& structures, 57(4): 605-622.

Shen, W. Y., Chow, Y. K., Yong, K. Y. (2000). A variational approach for the analysis of pile group-pile cap interaction. Geotechnique, 50(4): 349-357.

Souza, R. A., Kuchma, D. A., Park, J. Bittencourt, T. N. (2007). NonLinear Finite Element Analysis of Four-Pile Caps Supporting Columns Subjected to Generic Loading. Computers and Concrete 4(5): 363-376.

Suzuki, K., Otsuki, K. (2002). Experimental Study on Corner Shear Failure of Pile Caps. Japan's Transactions Concrete Institute 23.

Suzuki, K., Otsuki, K. Tsubata, T. (1998). Influence of Bar Arrangement on Ultimate Strength of Four-Pile Caps. Japan's Transactions Concrete Institute 20: 195-202.

Suzuki, K., Otsuki, K. Tsubata, T. (1999). Experimental Study on Four-Pile Caps with Taper. Japan's Transactions Concrete Institute 21: 327-334.

Suzuki, K., Otsuki, K. Tsubata, T. (2000). Influence of Edge Distance on Failure Mechanism of Pile Caps. Japan's Transactions Concrete Institute 22: 361-367.

Yang, Y., Masuda, T., Yoshida, E., Horiuchi, S., Kiriyama, T. (2020). Effect of pile arrangement on the bending performance of an existing bridge footing under lateral seismic loading. Latin American Journal of Solids and Structures, 17(2). 